\title{
Iron and Zinc Treatment in Iron Deficiency
}

\author{
Demir Eksikliğinde Demir ve Çinko Tedavisi
}

\author{
Beuy Joob1, Viroj Wiwanitkit2 \\ 1Sanitation 1 Medical Academic Center, Bangkok, Thailand \\ ${ }^{2}$ Hainan Medical University, Hainan, China
}

To the Editor,

The recent report by Özhan et al. was very interesting [1]. Özhan et al. concluded that "iron and zinc treatment instead of only iron replacement may be considered in cases of iron deficiency" [1]. The results from their study might support this suggestion. Nevertheless, we would like to add some comments. First, there was no complete nutritional evaluation in the patient and control groups, and there might have been some effects due to differences of intake among the subjects. In addition, it is not doubted that the patients had iron deficiency, but there is still the chance of the coexistence of other hemoglobin disorders. In Southeast Asia, concurrent iron deficiency and hemoglobinopathy are very common and can be misdiagnosed and incorrectly managed [2]. Iron supplementation in the case of combined iron deficiency and hemoglobinopathy has to be carefully considered $[2,3]$. Focusing on the serum zinc level, there is still no pathogenesis to explain the problem in the case of iron deficiency, but there is already a report confirming that hemoglobinopathy can result in low serum zinc levels [4]. Hence, to apply the recommendation of Özhan et al., further studies are required for validation, and attention to possible concomitant hemoglobinopathy is necessary [1].

Keywords: Iron, Zinc, Treatment, Deficiency

Anahtar Sözcükler: Demir, Çinko, Tedavi, Eksiklik

\section{Authorship Contributions}

Concept: Beuy Joob, Viroj Wiwanitkit; Design: Beuy Joob, Viroj Wiwanitkit; Data Collection or Processing: Beuy Joob, Viroj Wiwanitkit; Analysis or Interpretation: Beuy Joob, Viroj Wiwanitkit; Literature Search: Beuy Joob, Viroj Wiwanitkit; Writing: Beuy Joob, Viroj Wiwanitkit.

Conflict of Interest: The authors of this paper have no conflicts of interest, including specific financial interests, relationships, and/ or affiliations relevant to the subject matter or materials included.

\section{References}

1. Özhan 0, Erdem N, Aydoğdu i, Erkurt A, Kuku i. Serum zinc levels in iron deficient women: a case-control study. Turk J Hematol 2016;33:156-158.

2. Pansuwan A, Fucharoen G, Fucharoen S, Himakhun B, Dangwiboon S. Anemia, iron deficiency and thalassemia among adolescents in Northeast Thailand: results from two independent surveys. Acta Haematol 2011;125:186-192.

3. Burdick C. Combined iron deficiency and thalassemia minor. Am J Clin Pathol 2013;139:260.

4. Fung $E B$, Gildengorin $G$, Talwar $S$, Hagar L, Lal A. Zinc status affects glucose homeostasis and insulin secretion in patients with thalassemia. Nutrients 2015;7:4296-4307.

\section{Reply}

Dear Dr Joob,

Thank you for your comments and recommendations. We had evaluated the zinc deficiency in iron deficiency anemia, not in all anemia types. Serum iron, ferritin, and transferrin saturation levels were used in diagnosis and whether or not hemoglobinopathy exists, these patients were diagnosed iron deficiency anemia. And for possible mechanisms, there are some theories mentioned in the article. One of them is increase in production of Zn-protoporphyrin and usage of zinc instead of iron in the protoporphyrin structure [1], which can explain zinc deficiency in iron deficiency. And in another study, histopathological changes causing iron and zinc deficiency in intestinal mucosa were reversed with zinc treatment and the absorption of zinc and iron was improved [2]. But still as you mentioned and as we mentioned in our article, further studies are needed.

Onur Özhan, Neslihan Erdem, İsmet Aydoğdu, Mehmet Ali Erkurt, İrfan Kuku

\section{References}

1. Hastka J, Lassere JJ, Schwarzbeck, Hehlmann R. Central role of zinc protoporphyrin in staging iron deficiency. Clin Chem 1994;40:768-773.

2. Arcasoy A. İnsan sağlığında çinkonun önemi. TÜBiTAK Bilim ve Teknik Dergisi 1996;12:56 (in Turkish). 